\title{
O Uso das Técnicas Esten didas e o Conceito de Instrumento Musical em Helmut Lachenmann
}

\author{
The Use of Extended Techniques and the Concept \\ of Musical Instrument in Helmut Lachenmann
}

\author{
Sergio Kafejian \\ Universidade de São Paulo (USP) - Pós-Doutorado \\ NYU Steinhardt (Visiting Scholar) \\ kafejian@uol.com.br
}

\section{Silvio Ferraz}

Universidade de São Paulo

silvioferraz@usp.br

\begin{abstract}
Resumo: A obra do compositor alemão Helmut Lachenmann caracteriza-se pelo uso consistente e especulativo das técnicas instrumentais estendidas. Sua poética musical se desenvolve assim em um discurso que, negando os princípios organizacionais baseados na altura definida, propõe procedimentos de organização fundamentados nas características das sonoridades e seus aspectos técnico instrumentais. Em paralelo a sua produção composicional, Lachenmann propõe um corpo teórico no qual discute questões estéticas, técnicas e práticas que norteiam seus processos de composição. Neste artigo abordamos alguns conceitos propostos pelo compositor que estão diretamente relacionados à criação e formalização de novos métodos e procedimentos de organização composicional. O objetivo é assim identificar ferramentas e técnicas de manipulação e organização de material sonoro que possam ser utilizadas tanto em análises de obras do compositor quanto em processos composicionais autorais. A metodologia utilizada consistiu em reunir e interpretar o material teórico acerca dos conceitos que estão na base dos processos criativos do compositor, para, posteriormente, identificar em suas composições temA (1968) e Guero (1969) tais processos.
\end{abstract}

Palavras-chave: técnicas estendidas; instrumento musical; composição musical; análise musical; Helmut Lachenmann. 


\begin{abstract}
The work of Helmuth Lachenmann is characterized by being based on the consistent and speculative use of extended instrumental techniques. Thus, his musical poetics is strongly linked to the production of a musical discourse that, denying the organizational principles based on defined pitches, proposes procedures of organization based on the characteristics of the sonorities coming from the extended techniques. In parallel to his compositional production, the composer produced a theoretical body in which he discusses aesthetic, technical, and practical issues that guide his compositional processes. In this article, we discuss some concepts proposed by Lachenmann that are directly related to the creation and formalization of new methods and procedures of compositional organization. The objective of this work is to identify tools and techniques for manipulation and organization of sound material that can be used both in analyzes of the composer's works and in compositional processes. The methodology used consisted in gathering and interpreting the theoretical material about the concepts that are the basis of the creative processes of the composer, in order to, later, identify these compositional processes in his compositions temA (1968) e Guero (1969).
\end{abstract}

Keywords: extended technics; musical instrument; musical composition; musical analysis; Helmut Lachenmann.

\title{
1 - Introdução
}

Dentre os compositores europeus que na virada para a década de 1970 tiveram seus projetos poéticos calcados no uso ostensivo das técnicas estendidas destaca-se Helmut Lachenmann. Tal importância se dá pelo fato de o compositor alemão ter conseguido estabelecer estratégias composicionais em que tanto o agenciamento do material quanto o próprio material sonoro agenciado se colocam em um mesmo plano, permitindo a construção de um discurso baseado nas características dinâmicas, instáveis e complexas das sonoridades estendida ${ }^{1}$. Lachenmann propõe assim uma transformação da escuta musical, conduzindo o foco da atenção para elementos sonoros que mesmo já possuindo pertinências próprias na prática composicional da Música Concreta desenvolvida nos anos 1950, encontravam-se negligenciados na música de concerto ocidental. Para o compositor, tratava-se de reinventar a cadeia produtiva da música de concerto, reinvenção esta que partia dos meios de produção sonora e passava pelos paradigmas de organização, de recepção, compreensão e contextualização do discurso musical. Destarte, suas pesquisas entrelaçam os diversos campos de reflexão envolvidos nas práticas musicais, fazendo com que transformações operadas em uma esfera incorram diretamente em transformações nas demais. Neste artigo nos circunscrevermos a três aspectos que consideramos fundamentais para a compreensão do pensamento do compositor alemão no campo da composição musical, a saber: (1) a ideia de que compor é inventar um

\footnotetext{
${ }^{1}$ Neste artigo usaremos, circunstancialmente, o termo sonoridade estendida par a nos referirmos às sonoridades advindas das técnicas estendidas.
} 
instrumento musical, (2) as estratégias de elaboração e manipulação das sonoridades estendidas com base no que chamou de música concreta instrumental, (3) as estratégias de projeção das sonoridades estendidas na organização temporal, a partir da concepção do que elabora em sua proposta de tipologia sonora da música contemporânea.

\section{2 - O Instrumento musical em Lachenmann}

A radical transformação do uso do instrumento musical é um elemento fundante na construção da poética musical de Helmut Lachenmann. A exploração sistemática e exaustiva de todas as possibilidades de obtenção de material sonoro, assim como a apropriação do uso do embate físico entre a energia mecânica do instrumentista e o corpo material que constitui o instrumento configuram o campo de imanência a partir do qual o compositor desenvolve seu discurso musical. As reflexões a propósito do instrumento musical em Lachenmann encontram-se intrinsecamente ligadas às reflexões acerca da prática instrumental, dos componentes da sonoridade e dos paradigmas da composição. A seguir, abordaremos três ideias presentes no pensamento do compositor alemão acerca da prática instrumental que transformaram o conceito de instrumento musical, sendo elas: (1) a ideia de que um instrumento é um mediador entre energias físicas e acústicas; (2) a ideia de que o instrumento não é algo dado, mas sim, algo a ser "construído"; (3) por fim, a ideia de que o instrumento é um dispositivo de produção sonora a ser explorado em toda sua extensão física e sonora.

\section{1 - Instrumento e fisicalidade}

Em vários textos de Helmut Lachenmann podemos encontrar reflexões que vinculam as categorias sonoras instrumentais aos gestos físicos que as produzem. São proposições que atrelam as características acústicas de cada sonoridade com as categorias de força física e os modos de aplicação dessas forças no instrumento. Nesta concepção, as sonoridades seriam o resultado do encontro de uma força física mecânica - aplicada pelo instrumentista -, com a resistência material oferecida pelo instrumento:

[...] o que soa não soa em função da sonoridade ou de sua utilização estrutural, mas sinaliza a utilização concreta da energia no instante em que se efetuam os gestos dos músicos, nos fazendo sentir, escutar, suspeitar as condições mecânicas dessas ações e as resistências que elas encontram. (Lachenmann apud Kaltenecker 2009, p. 12)².

2 Todas as traducões para o português são dos autores. 
Tal afirmação implica em uma nova atitude perante os procedimentos de construção composicional, que passam a ter nas ações mecânicas e físicas um novo campo de atuação. A este respeito, o musicólogo Didier Guigue afirma que grande parte das posições estéticas de Lachenmann "se concentra no problema da corporalidade do sonoro instrumental e da sua integração à estruturação musical" (Guigue 2011, p.289).

Com isso, a investigação composicional não estaria circunscrita somente às esferas tradicionais de altura, intervalo e ritmo mas se estenderia sobretudo para as esferas da fisicalidade relacionada à produção sonora. A este respeito, podemos ler em Lachenmann:

\begin{abstract}
O som, portanto, nãoé mais considerado como um elemento a ser variado sob os aspectos do intervalo, da harmonia, do ritmo, etc., mas antes de tudo como o resultado da aplicação de uma força mecânica sob condições físicas que são controláveis e variáveis pela composição: o som do violino compreendido e regulado como resultado de uma fricção entre característica entre dois objetos característicos, entre outros modos de fricção e de objetos (Szendy 1997, p. 74).
\end{abstract}

Podemos entender que, para o compositor alemão, criar relações entre material musical passa a ser também criar relações entre as forças e os gestos físicos que determinam e condicionam essas sonoridades. A estratégia de Lachenmann para inserir os gestos e as ações físicas no centro das estruturações musicais consiste na criação de novos repertórios de gestos instrumentais (Hockings 1995, p. 13), que podem surgir tanto de processos de desconstrução de técnicas instrumentais tradicionais (Ryan, Lachenmann 1999, p. 21) quanto da troca de características de modos de jogos instrumentais entre família de instrumentos (Lachenmann 2009, p. 96). No que diz respeito à desconstrução das técnicas instrumentais podemos entender a dissociação e posterior re-associação dos diversos gestos e ações presentes em um modo de ataque tradicional. Como exemplo, podemos citar: a dissociação do movimento do braço de uma arcada com a direção ao qual esta arcada está associada; a dissociação da ação de produzir uma coluna de ar com o diafragma da ação de fazer o lábio vibrar no bocal de um trombone; a dissociação dos movimentos das mão esquerda e direita de um violonista. Quanto à troca de modos de jogos instrumentais entre famílias de instrumento podemos pensar em golpes de percussão acionando as teclas de um piano; os pinçamentos característicos do toque de uma harpa excitando as cravelhas de um violino; os movimentos de braço de uma arcada raspando a pele de um tímpano. Em Lachenmann, a sistematização dos procedimentos de desconstrução e reconstrução dos diversos gestos são os principais caminhos para o estabelecimento de um novo arcabouço de modos de produção sonora, de sonoridades e de organização de material musical. 
Sendo assim, o que observamos em Lachenmann, assim como também desponta em outros compositores na virada para os anos 1970 (como Brian Ferneyhough) é que o instrumento musical deve ser compreendido em uma cadeia de transdução energética que compreende um sistema complexo de excitadores, corpos excitados, estruturas de transmissão, ressonância e difusão. O caminho de Lachenmann será assim aquele que interpõe ações de desvio nas práticas tradicionais de tal cadeia, conduzindo à realizações sonoras e técnicas distintas daquelas da tradição clássico-romântica, as quais associamos então à noção de técnica-estendida. É assim que compor será construir um instrumento, imaginar sua cadeia de transdução do ponto de excitação à difusão sonora, com base em novas sonoridades.

\section{2 - Instrumento e construção}

Para Lachenmann um instrumento não é algo dado de antemão, mas sim algo a ser construído ou mesmo a ser descontruído. A despeito dos parâmetros e padrões habituais das sonoridades e técnicas de execução dos instrumentos, é na descoberta de novas sonoridades e de novos modos de se tocar um instrumento que esse se constrói. Para o compositor alemão, um violino - enquanto ferramenta de expressão artística - não é apenas um violino, mas é o instrumento que carrega consigo um "nome próprio": o violino-Paganinni, o violino-Bach, o violino-Xenakis e por fim o violino-Lachenmann,. Ou seja, é através da expressividade própria e peculiar que cada compositor imprime nos instrumentos, das sonoridades que intenciona bem como suas na estrutura musical, que os instrumentos se reconfigurariam.

Em suas reflexões tal construção não se circunscreve somente aos instrumentos em sua individualidade, mas se estende aos grupos instrumentais, homogêneos ou não. Um novo instrumento também pode ser construído a partir do encontro de diversos instrumentos. Assim, temos o instrumento flautavioloncelo-voz-Lachenmann, o instrumento piano-violino-trompa-Brahms, ou ainda, o quarteto de cordas-Bartók, o quarteto de cordas-Ligeti, e assim por diante. Tal é a importância dada ao conceito de construir um instrumento musical, que o compositor chega a afirmar:

[...] "compor quer dizer: construir um instrumento e tocá-lo". Mas se trata justamente de uma imbricação tão intensa entre a articulação do tempo e a do som que não somente o som, mas as relações sonoras elas mesmas, se dariam em função deste "instrumento imaginário" (Lachenmann 2009, p.137).

O ponto aberto e explorado por Lachenmann no uso que faz dos instrumentos não se restringe às alterações simples na cadeia de produção sonora (de transdução da energia de excitação à difusão do som) herdadas das tradições 
barroco-clássico-românticas, como os pontos de contato arco-corda, usos extremos de harmônicos, jogos de pressão de arco, ou nos sopros as expansões realizadas com controles extremos de coluna de ar, de uso da voz em associação à emissão ordinária instrumento. Lachenmann toma cada instrumento como uma interface sonora. Com isso, os instrumentos tradicionais terão a integralidade de suas superfícies sonoramente exploradas: as teclas, as madeiras das caixas de ressonância, as cravelhas, as chaves de registro, os cavaletes, enfim toda a estrutura física que compõem um instrumento. Explorar um instrumento, tatear um instrumento.

\section{3 - Instrumento e exploração - o tatear}

O conceito do tatear é extremamente importante no pensamento do compositor e se estende a várias esferas da prática musical. No que diz respeito ao campo da invenção e construção instrumental podemos compreender $o$ "tatear" enquanto: (1) exploração tátil, exploratória de toda a superfície de produção sonora de um instrumento; (2) processo de desconstrução das sonoridades de um instrumento estendendo o uso tradicional de produção sonora ou expandindo sua superfície musicalmente pertinente; (3) elaboração de um novo universo sonoro para um instrumento, ou grupos de instrumentos; (4) descoberta de novas funções e possibilidades instrumentais em um instrumento ${ }^{3}$.

É importante ressaltar que o tatear não se restringiria apenas a explorar e reinventar os instrumentos tradicionais, mas se apresentaria também como um meio de dar forma ao que o compositor denomina de "instrumentos imaginários". Estes, são instrumentos que surgem das descobertas de categorias sonoras que entrecruzam instrumentos e famílias de instrumentos. Um exemplo oferecido pelo compositor nos permite compreender como o processo de construção de um instrumento imaginário pode se dar: um som de piano em stacatto seguido de um som de um ataque em um prato suspenso imediatamente abafado se apresentam enquanto eventos que podem ser o "toque de um instrumento imaginário não explorado" do qual podemos "deduzir sua configuração geral, para em seguida a modificar, seguindo ou indo de encontro às regras da arte, acentuar as contradições da configuração de forma chegar ao desconhecido" (Lachenmann 2009, p. 137).

Ou seja, seria no estabelecimento de famílias de sonoridades, que não estariam atreladas a um só instrumento que este instrumento virtual, imaginário, se constituiria. Podemos pensar em algo como um meta-instrumento, cujas sonoridades atravessariam obliquamente o efetivo instrumental disponível e cuja lógica de agrupamento seriam as características acústicas das sonoridades. Sons

${ }^{3}$ Cf. Lachenmann 2009, p.135. 
aerados, sons de clicks, sons de fricção, sons de alturas definidas que circulariam pelos diversos instrumentos disponíveis.

Tal aspecto já vinha sendo elaborado pelo compositor desde a produção de seu artigo "Tipos sonoros da nova música”, trabalhado por Lachenmann em versões distintas entre os anos de 1966 e 1993, e que acompanham seu processo composicional desde obras inaugurais como Intérieur I (1966), para percussão, e Pression (1969-1970), para violoncelo solo, conduzindo a sua escrita até Grido (2001), quarteto de cordas em que sintetiza parte deste período de pesquisa. Em seu artigo Lachenmann observa tais sonoridades compostas, realizadas através da associação de diversos instrumentos para compor um só grande instrumento, em outros compositores como Stockhausen, Ligeti, Penderecki, Nono, elencando o que entende por Som-cadencia (KadenzKlang) e suas derivações (som-flutuação, som-sedimentar, som-decaimento, som-cor, som-textura e som-estrutura) e de como tal ideia figura na sua composição de Interieur I para percussão.

Mas, diferentemente desses compositores, é importante em Lachenmann o caráter exploratório experimental através do tatear. $\mathrm{O}$ tatear enquanto descoberta do instrumento através do "tocar de uma certa maneira, às cegas, encontrar e inventar outros toques [...] fazendo funcionar o instrumento imaginário por esta abordagem tateante" (Lachenmann 2009, p. 138).

O conceito de tatear não se aplica somente ao processo de construção e descoberta do instrumento, mas também ao dispor e agenciar no tempo os sons advindos desses instrumentos. E, por último, se aplica também ao campo da escuta e da recepção da obra musical. Sendo assim o tatear é também o mergulhar na percepção das estruturas sonoras de forma a encontrar a organização e a disposição de sons e estruturas, sons e estruturas que "só podemos nela penetrar pouco a pouco, avançar tateando através de seus componentes ordenado no tempo [...]" (Lachenmann 2009, p. 135).

\section{3 - As sonoridades estendidas em Lachenmann}

Se o campo de ação do compositor alemão se dá na esfera das sonoridades advindas das técnicas estendidas, como essas sonoridades são concebidas, elaboradas e manipuladas dentro de sua poética? Para Lachenmann, cada sonoridade institui-se enquanto um ponto de encontro entre diversas linhas de direcionamento ${ }^{4}$. A este respeito o compositor afirma:

\footnotetext{
${ }^{4} \mathrm{O}$ conceito da sonoridade enquanto um ponto sendo atravessado por diversas linhas foi sugerido primeiramente por Stockhausen, como esclarece Lachenmann em entrevista concedida a Peter Szendy (Szendy 1997).
} 
Eu considero cada elemento sonoro como um ponto pertencente a uma infinidade de linhas que conduzem a uma infinidade de direções. Compor significa escolher e montar seu sistema de linhas novas, tratando este ponto como um grau de uma escala transcendente que transforma e individualiza sua evidência acústica" (Szendy 1997, p.69-70).

Portanto, cada sonoridade é concebida como pertencente a uma estrutura latente a ser evidenciada - ou mesmo construída -, e o ato de compor consistiria tanto em encontrar e determinar essas linhas quanto em criar relações estruturais variadas entre elas. Para exemplificarmos este procedimento de elaboração propomos analisar uma sonoridade presente na obra tem $A(1968)^{5}$, para flauta, violoncelo, e voz. Neste caso, um som curto e ruidoso advindo do uso de uma arcada com extrema pressão de arco, conhecida como ecrasé ou scratch-tone, no violoncello.

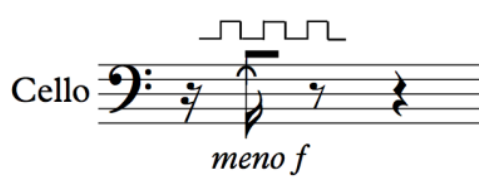

Exemplo 1: sonoridade ecrasé presente no quinto tempo com compasso 147 de tem $A$.

Esta sonoridade, como podemos sugerir, está associada a diversas escalas de valores a partir das quais o compositor pode criar suas redes de relação e significação, seriam elas:

1) Linha que percorre as direções entre o arco ecrasé e o arco flautato.

2) Linha que percorre as direções entre o registro grave e o registro agudo.

3) Linha que percorre as direções entre o som de curta duração e o som longo.

4) Linha que percorre as direções entre o ruído e o som puro.

5) Linha que percorre as direções entre o violoncelo, a flauta e a voz.

6) Linha que percorre as direções entre o pianíssimo e o fortíssimo.

$\mathrm{Na}$ imagem abaixo, podemos visualizar como estas linhas podem se interrelacionar e, através dos pontos vermelhos, identificar em que ponto das linhas a sonoridade da figura 1 se encontra.

\footnotetext{
${ }^{5}$ Exemplos transcritos pelos autores a partir da edição lançada em 1980 pela editora Breitkopf \& Hartel.
} 


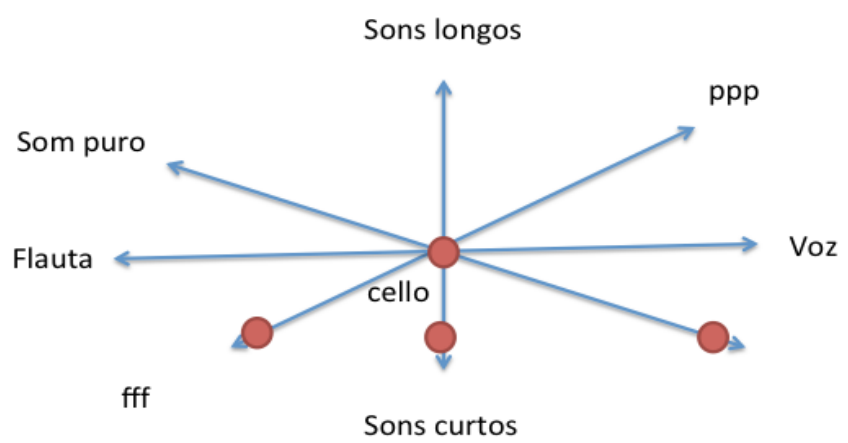

Figura 1: gráfico de linhas que determinam a sonoridade do Exemplo 1.

Neste gráfico, proposto pelos autores, estão presentes as linhas de orientam a sonoridade entre: som longo/som curto; som puro/ruído; flauta/cello/voz; fortíssimo/pianíssimo. Cada ponto vermelho discrimina em que ponto de cada uma dessas linhas a sonoridade em questão se encontra.

Tendo construído essas linhas e encontrado a localização da sonorida de em cada uma delas, podemos elaborar uma série de transformações direcionais que percorrem essas linhas. Podemos pensar, entre muitas outras, nas seguintes transformações: (1) transferir esta sonoridade para a voz - atuando sobre a linha que transita entre os instrumentos do efetivo instrumental da peça-; (2) aumentar o tempo de duração da sonoridade - atuando sobre a linha que transita entre sons longos e sons curtos -; (3) fazer uso de um arco em pressão de harmônico - atuando sobre a linha que transita entre o ruído e som puro.

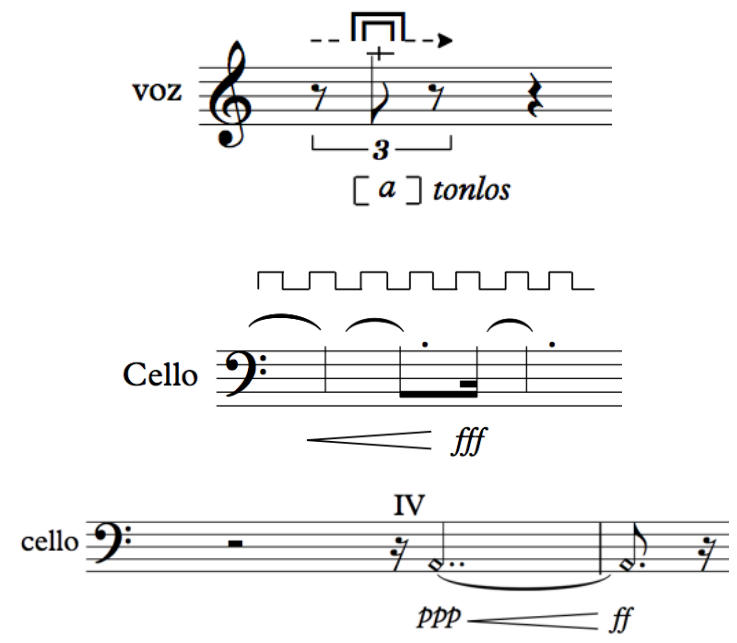

Exemplo 2: sonoridades extraídas de tem $A$, sendo que o exemplo superior encontra-se no primeiro tempo do compasso 51; o exemplo intermediário encontra-se nos três primeiros tem pos do com passo 171; o exemplo inferior encontra-se nos entre o terceiro tem po do compasso 2 e o primeiro tem po do compasso 3. 
Vale ressaltar que Lachenmann, em diversas de suas peças, se vale de tais escalonamentos que nos remetem claramente aos escalonamentos de Pierre Schaeffer em sua Morfotipologia dos objetos sonoros e sempre orientado por um "solfejo de sons homogêneos": conforme massa, dinâmica, timbre harmônico, perfil melódico, perfil de massa, grão e allure.

\section{1 - Guero}

Outra peça que nos ajuda a compreender como Lachenmann elabora e manipula suas sonoridades é a peça Guero, escrita em 1969, para piano solo. Nela, podemos encontrar os principais elementos que caracterizam a pesquisa artística do compositor, do caráter provocativo e de recusa aos modelos estabelecidos dos códigos estéticos e de execução instrumental da música de concerto à edificação de um fazer musical radicalmente original $^{6}$. Nesta obra o piano nunca é executado da maneira tradicional, ao invés disso, o compositor faz uso de raspagens dos dedos e das unhas por cima e ao lado das teclas ${ }^{7}$, de toques e raspagens realizados diretamente nas cordas do piano, de sons extraídos através do acionamento violento dos pedais, de sons percutidos no corpo do instrumento e, finalmente, de sons extraídos através de gestos de pinçamento - similar a tocar um violão ou uma harpa -, realizados com os dedos tanto nas cravelhas das cordas quanto nas cordas e teclas do piano. No entanto, não obstante a grande variedade de meios de produção sonora utilizada em Guero, as sonoridades presentes na peça podem ser agrupadas em duas grandes famílias, que resumem tanto as qualidades sônicas quanto às ações físicas de execução instrumental: raspagens e ataques. Desta forma, as diversas sonoridades que se apresentam na peça se configuram a partir de transformações operadas nas linhas de direcionamento construídas sobre as duas famílias sonoras fundamentais. E é exatamente nas transformações dos diversos modos de produzir essas sonoridades, tendo como eixo as linhas de direcionamento, que o jogo composicional se institui. Na tabela abaixo podemos acompanhar as diversas variações, tanto de modo de ataque quanto de região do instrumento, a que são submetidas as duas famílias de sonoridades.

\footnotetext{
6 Para o compositor e musicólogo Didier Guige em Guero Lachenmann, além de concretizar seu ideal de sonoridades pianísticas, expressa "a essência de suas ideias sobre a função sóciocrítica da música" (2011, p.291).

${ }^{7}$ Este modo de executar o instrumento deixa claro a referência, já explícita no título da peça, ao instrumento guero, que no Brasilé conhecido como reco-reco.
} 


\begin{tabular}{|l|l|}
\hline \multicolumn{1}{|c|}{ RASPAGENS } & \multicolumn{1}{|c|}{ ATAQUES/PIZZICATOS } \\
\hline Realizadas com a unha do dedão & Embaixo das teclas \\
\hline $\begin{array}{l}\text { Realizadas com a unha do dedo médio } \\
\text { esticado }\end{array}$ & No corpo do instrumento (lateral) \\
\hline $\begin{array}{l}\text { Realizadas com as unhas de três dedos } \\
\text { curvados }\end{array}$ & No pedal \\
\hline Realizadas com a unha de um dedo esticado & Nas cravelhas \\
\hline $\begin{array}{l}\text { Realizadas com as unhas de vários dedos } \\
\text { esticados }\end{array}$ & Na harpa (entre as cravelhas e o feltro) \\
\hline Na lateral frontal das teclas & Nas cordas \\
\hline Em cima das teclas brancas & \\
\hline $\begin{array}{l}\text { Simultaneamente na lateral frontal das teclas } \\
\text { pretas teclas e em cima das teclas brancas }\end{array}$ & \\
\hline Em cima das teclas pretas & \\
\hline Nas cravelhas & \\
\hline Na harpa (entre as cravelhas e o feltro) & \\
\hline
\end{tabular}

Tabela 1: Modos de ataque e regiões do piano a serem excitadas.

Tabela realizada a partir das instruções que aparecem na partitura de Guero.

Ao analisarmos essas indicações que aparecem na bula podemos traçar as linhas fundamentais de direcionamento. Para as raspagens teríamos: (1) a linha que transita entre as diversas localizações nas quais são realizadas as raspagens, (2) a linha que determina com qual, quantos e em que posição de dedos as raspagens devem ser realizadas. Para os ataques teríamos somente a linha que transita entre as localizações dos ataques. Vale ressaltar que sobre estas sonoridades ainda operam as variações controladas de: dinâmica, registro, região do instrumento, pedalização e, no caso das raspagens, variações na velocida de da execução ${ }^{8}$.

Podemos então verificar que não são os sistemas de alturas definidas ou os sistemas harmônicos que conduzem as estratégias de elaboração composicional, mas sim as qualidades acústicas das sonoridades, as transformações das ações gestuais e mecânicas que as produzem, as transformações tímbricas internas e suas decorrências na resultante global, aí implicados: registro, ressonância, rugosidade, duração, espectro, entre outros elementos da sonoridade. Destarte, Guero explicita os conceitos abordados anteriormente de construção de um instrumento através da exploração de novos modos de se tocar; da elaboração de famílias de sonoridades; e finalmente, da criação de linhas que operam transformações variadas nas sonoridades. E ainda, em Guero, fica latente a ideia Lachenmanianna de que construir um instrumento,

\footnotetext{
8 Para uma análise mais aprofundada das transformações operadas nestes parâmetros em Guero ver Ribeiroe Ferraz 2017.
} 
explorar um instrumento e compor são ações estreitamente entrelaçadas e mutuamente implicadas.

\section{Organização do material em Lachenmann: o arpejo e as regiões formânticas}

Mas se podemos vislumbrar como Lachenmann concebe seus materiais a partir de categorias sonoras, resta-nos saber como se dá a projeção destas sonoridades nas estruturas de longo termo, ou seja, no tempo. Para tal, iremos nos aproximar de duas proposições colocadas pelo compositor: o conceito de arpejo e o conceito de formante. O conceito de arpejo se relaciona diretamente com a ideia de que compor seria construir um instrumento e tocá-lo. Pois, se um instrumento se configuraria enquanto um amplo espectro de sonoridades que seriam agrupados em categorias sonoras definidas por suas características acústicas, gestuais e físicas, o arpejo - denominação metafórica criada por Lachnemann -, seria seu mecanismo imaginário de "execução". A respeito da interação entre todas essas instâncias da prática composicional, escreve $\mathrm{o}$ compositor:

Como uma espécie de arpejo imenso sobre este instrumento-som-forma imaginário. Cada uma das cordas desta harpa imaginária seria não somente escolhida, mas concebida pelo compositor como um objeto mais ou menos complexo, a partir de materiais pré-existentes. A ordem mesma destas cordas entraria como uma parte essencial desta construção. Talvez algumas destas cordas imaginárias seriam elas mesmas, instrumentos locais, subgrupos de instrumentos, quase como que feixes de cordas, e as afinidades perceptíveis entre estas cordas, mais ou menos distanciadas uma das outras, abrem milhares de possibilidades de se construir pontes entre elas (Lachenmann 2009, p.114-115).

Mas, se o conceito de arpejo nos ajuda a compreender como se dão as organizações das sonoridades nas estruturas de médio termo, é com o conceito de formante que podemos compreender como Lachenmann projeta suas estruturas na forma global. Para o compositor, é através da recorrência de agrupamentos de categorias sonoras - homogêneas ou não -, que uma obra se dispõe no tempo. Essas recorrências, às quais o compositor denomina de "formantes", seriam momentos de pregnância de materiais sonoros que de tempos em tempos criariam zonas de polarização de determinados materiais. A este respeito afirma o compositor:

[...] eu prefiro reunir, quase por indução, diferentes objetos sobre o teto da mesma peça: então estes objetos adquirem a função de formantes - que pela estratégia da estruturação - dão um sentido novo a ideia mesma de uma consonância global, que delas resultam e da qual elas fazem parte (Szendy 1997, p.73).

\section{MUSICA THEORICA}


Podemos notar que estas regiões "formânticas" podem ser concebidas enquanto arpejos dilatados, pois, se os arpejos locais determinam relações entre materiais próximos, os arpejos globais determinariam as relações distanciadas entre os materiais. $\mathrm{Na}$ figura abaixo, podemos acompanhar as regiões "formânticas" na obra tem $A$, assim como identificadas pelos autores. Nesta figura, cada cor representa a polarização de uma família de materiais sonoros estruturados a partir de suas características acústicas.

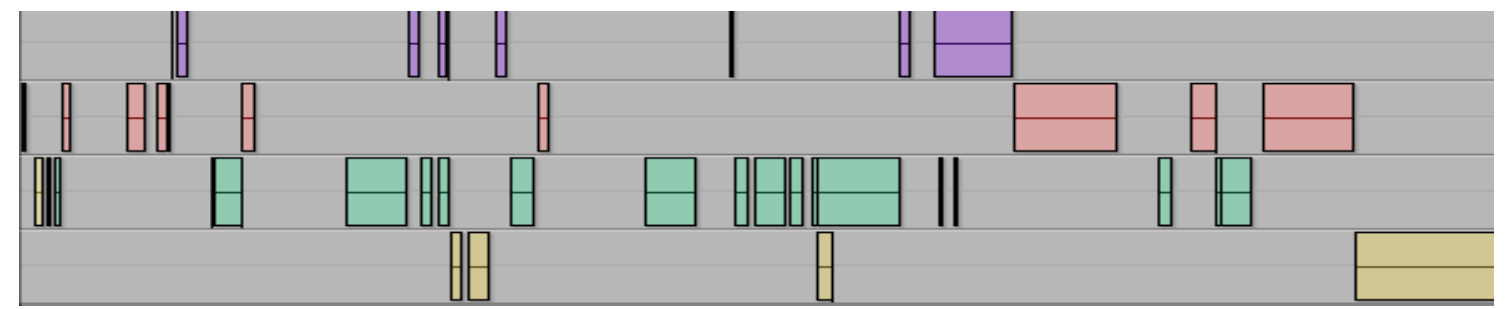

Figura 5: mapa das regiões formânticas $\operatorname{de} \operatorname{tem} A$, realizada no software Pro Tools a partir do sonograma da gravação de 1994 presente no CD Helmut Lachenmann II, realizado pelo Ensemble Recherche.

\section{5 - Escuta e percepção do dado sonoro}

Eu falo algumas vezes de uma nova virgindade do som: o som como experiência convencional, como elemento conhecido está sempre já maculado, carregado de convenções e, finalmente impuro. O trabalho do compositor consiste em criar um contexto que possa lhe tornar novamente intacto, int acto sob um novo aspecto (Szendy 1997, p.70).

Algumas das grandes questões que se colocam, quando do uso ostensivo de sonoridades estendidas no processo composicional dizem respeito à estreita ligação entre as técnicas composicionais desenvolvidas na música de concerto ocidental e os sistemas musicais baseados em notas musicais de alturas definidas. Sendo assim, como compor fazendo o uso de sonoridades ruidosas, instáveis e refratárias às estratégias de hierarquização da música de alturas definidas? Como encontrar meios de sensibilizar e mobilizar uma escuta condicionada pelas estratégias teleológicas das narrativas tradicionais? As respostas dadas pelos compositores para tais questionamentos acabaram por colocar em xeque os modelos de escuta habituais e trouxeram para o primeiro plano dos processos construtivos elementos do som até então negligenciados. Pois, para que novos modelos de agenciamento e organização do material sonoro se impusessem, seria imprescindível que a escuta musical se sensibilizasse para novas categorias de parametrização do som, e que, por outro lado, o pensamento musical pudesse 
descobrir novos campos de atuação para colocar em marcha seus processos construtivos. No que diz respeito a Lachenmann, este encontrou nos processos de desconstrução das estruturas presentes nos materiais musicais o caminho para o surgimento de novos modelos organizacionais assim como para novos modelos de escuta. Lachenmann partiu do pressuposto de que cada sonoridade traz consigo toda uma cadeia de significações e expectativas que, de certa forma, neutralizam o potencial expressivo dos eventos sonoros, tornando-os reféns de condicionamentos e hábitos já sedimentados. Portanto, fazia-se necessário um trabalho de descondicionamento e de re-apropriação dos potenciais expressivos dos diversos parâmetros que compõe um som. A este respeito, podemos ler:

Quebrar as estruturas dominantes [que estão presentes nos materiais]: extrair dessas estruturas os elementos sonoros concretos, separá-los, quebrá-los, arrancá-los de suas conexões até então dominantes, dos quais as funções parecem-lhe próprias, afim de lhes atribuir, de um mesmo golpe, novas categorias, novas faturas [...] fazer uma experiência nova do que é familiar no contexto de novas conexões, portanto mobilizar a percepção, ativá-la de uma maneira nova (Lachenmann 2009, p.114-115).

Para o compositor fazia-se necessário uma atitude estética radical que transformasse a experiência da escuta, tirando-a de sua passividade e impondo a ela novos desafios perceptivos e existenciais. Tratava-se de negar o musical assim como conhecido até então - para adentrar em um novo universo de organização sonora. Em sua proposta de "ruptura dialética com o que é familiar" (Lachenmann 2009, p. 174), Lachenmann procura conscientemente a "nãomúsica", ou seja, o momento no qual todos os elementos musicais comumente codificados encontram-se ausentes, momento no qual a verdadeira liberdade de expressão se instaura: "é somente se engajando nesta experiência da não-música que escutar se torna perceber [...]. É lá que começamos a escutar de outra maneira" (Lachenmann 2009, p. 174).

\section{6 - Música Concreta Instrumental}

Embora refira pouco em seus textos e entrevistas, a referência a uma composição musical que tem por base a escuta é sem dúvida a proposta da música concreta proposta por Pierre Schaeffer. Não à toa, em seu artigo L'écoute est désarmée - sans l'écoute, Lachenmann emprega o termo musique concrète instrumental citado em francês. A distinção entre sua proposta e aquela de Schaeffer estará no fato de Lachenmann ter no instrumento, na fonte sonora acústica, um importante elemento de escuta, sobretudo para realizar sua ideia de descontrução do instrumento musical tradicional, enquanto ocompositor francês 
fará uso de gravações das mais variadas fontes sonoras presentes no cotidiano para elaborar suas construções sonoras. É também muito próxima a Schaeffer a ideia do tatear e a abordagem de um instrumento musical como "dispositivo para obter uma coleção variada de objetos sonoros mantendo presente o espírito da permanência de uma causa" (Schaeffer 1966, p.51) expandindo a ideia de permanência para além da materialidade do instrumento mas com base no "elemento permanente, comum a todos objetos sonoros nascidos de um mesmo instrumento": o timbre (permanência instrumental), os registros instrumentais (fonte de variações ditas "abstratas") e o jogo instrumental (fonte de variações ditas "concretas") (Idem, p. 55-56).

Não se trata assim apenas de ampliar o quadro de sonoridades de um instrumento indo além das resultantes barroco-clássico-românticas, mas da importância da análise do objeto sonoro e de seu escalonamento em estruturas sonoras nascidas não de um processo abstrato a priori mas do "estudo dos objetos" aberto a um objeto de três dimensões heterogêneas (tempo, comportamento espectral e amplitude) (Schaeffer 1996, p. 495). Criar com os sons um escalonamento, como propôs Schaeffer (Idem, p. 303).

\section{7 - Considerações finais}

A produção teórica de Helmut Lachenmann é extremamente profícua, tendo sido realizada concomitantemente com sua produção composicional. Através dela podemos acompanhar um pensamento rigoroso e consequente cujas proposições podem ser encontradas diretamente em suas obras musicais. Sendo assim, ler, escutar e analisar Lachenmann tornam-se ações complementares que conduzem à compreensão de suas atitudes artísticas, políticas e sociais. Neste processo encontramos um pensador consciente de suas responsabilidades perante o momento histórico no qual encontra-se inserido e cujos postulados e conceitos nascem e se fortalecem no seio de questionamentos comuns a vários compositores. Sendo assim, não é difícil contextualizar o diálogo que o compositor alemão estabelece com vários pensadores e compositores, entre eles, além de Pierre Schaeffer, podemos citar: o conceito de "instrumento construído" com o piano preparado de John Cage; as "linhas de direcionamento de sonoridades" com as proposições de Stockhausen, em especial, quando este desenvolve seus trabalhos envolvendo eletrônica e instrumento; e sua preocupação com a "virgindade da escuta" com as proposições de Salvatore Sciarrino acerca da liberação da escuta. No entanto, a originalidade, persistência e profundidade com que Lachenmann apropria-se de cada aspecto dos questionamentos do fazer musical contemporâneo fazem com que seu trabalho 
se destaque, ao longo dos anos, pela consistência e consequência de suas investigações.

Se fizemos um recorte bastante preciso dentro de sua produção teórica, tal fato se deu em função de um desejo de fornecer ferramentas tanto para a formalização de técnicas composicionais que fazem uso de técnicas estendidas, a serem usadas por compositores e estudantes de composição, quanto para que a análise da obra musical do compositor alemão possa ter como fundamento as grandes questões que compõem e caracterizam suas especificidades enquanto criador.

\section{Agradecimentos}

Agradecimentos à Fundação de Amparo à Pesquisa do Estado de São Paulo/FAPESP pelo apoio às pesquisas dos autores, processos no $n^{0}$ 2015/20236-4 e 2016/08036-2.

\section{Referências}

1. Guigue, Didier. 2011. Estética da sonoridade: A Herança de Debussy na música para Piano do Século XX. São Paulo: Perspectiva; João Pessoa: UFPB.

2. Hockings, Elke. 1993. A Portrait of Helmut Lachenmann. In: Tempo, New Series, No185, German Issue, p. 4-10; 12-14. UK: Cambridge University Press

3. 1995. Helmut Lachenmann's Concept of Rejection. In: Tempo, New Series, No193, German Issue, p. 4-10; 12-14. UK: Cambridge University Press

4. Kaltenecker, Martin. 2009. Introduction. In: Écrits et Entretiens. Paris: Contrechamps Éditions.

5. Lachenmann, Helmut. 1980. temA. Partitura. Alemanha: Breitkopf \& Härtel.

6. Lachenmann, Helmut. 2004. Klangtypen der Neuen Musik. In: Musik als existentielle Erfahrung, p. 1-20. Wiesbaden: Breitkopf und Härtel.

7. 2009. Écrits et Entretiens. Paris: Contrechamps Éditions. 
8. Ribeiro, Guilherme; Ferraz, Silvio. Guero: música concreta instrumental e direcionalidade na peça-estudo para piano de Helmut Lachenmann. Revista Vórtex, v.5, n.1, p.1-22.

http://vortex.unespar.edu.br/ribeiro_ferraz_v5_n1.pdf

9. Ryan, David; Lachenmann, Helmut. 1999. Composer in Interview: Helmut Lachenmann. In: Tempo, New Series, No. 210, p. 20-24. UK: Cambridge University Press.

10. Szendy, Peter. 1997. Entretien avec Helmut Lachenmann. In: Musiques en Création, p. 65-76. Paris: Contrechamps Éditions. 